\title{
Effect of Virgin Olive Oil (Olea europea. L) on Kidney Function Impairment and Oxidative Stress Induced by Mercuric Chloride in Rats
}

\author{
${ }^{1}$ Youcef Necib, ${ }^{1}$ Ahlem Bahi, ${ }^{2}$ Sakina Zerizer, \\ ${ }^{3}$ Cherif Abdennour and ${ }^{3}$ Mohamed Salah Boulakoud \\ ${ }^{1}$ Department of Biochemistry and Biological Cellular and Molecular, \\ ${ }^{2}$ Laboratory of Microbiological Engineering and Application, \\ Faculty of Sciences, Mentouri University, BP 25000 Constantine, Algeria \\ ${ }^{3}$ Animal Ecophysiology Laboratory, \\ Faculty of Sciences, Badji Mokhtar University, BP12 Sidi Amar, Annaba, Algeria
}

Received 2013-08-26; Revised 2013-10-02; Accepted 2013-10-21

\begin{abstract}
The study was designed to investigate the possible protective role of virgin olive oil in mercuric chloride induced renal stress, by using biochemical approaches. The effects of virgin olive oil on mercuric chloride induced oxidative and renal stress were evaluated by serum creatinine, urea and uric acid levels, kidney tissue lipid peroxidation, GSH levels, GSH-Px and GST activities. Administration of mercuric chloride induced significant increase in serum: interleukine1, interleukine6 and Tumor Necrosis Factor $\alpha(\mathrm{TNF} \alpha)$ levels, creatinine, urea and uric acid concentration showing renal stress. Mercuric chloride also induced oxidative stress, as indicate by decreased kidney tissue of GSH level, GSH-Px and GST activities along with increase the level of lipid peroxidation. Furthermore, treatment with mercuric chloride caused a marked elevation of kidney weight and decreased body weight. Virgin olive oil treatment markedly reduced elevated serum: IL1, IL6, TNF $\alpha$, creatinine, urea and uric acid levels and conteracted the deterious effects of mercuric chloride on oxidative stress markers changes caused by $\mathrm{HgCl}_{2}$ in kidney. Our results indicate that virgin olive oil could have a beneficial role against mercuric chloride induced oxidative and renal stress in rat.
\end{abstract}

Keywords: Antioxidant Enzymes, Mercury, Pro-Inflammatory Cytokine, Renal Stress, Virgin Olive Oil

\section{INTRODUCTION}

Mercury is a well-known human and animalinduces extensive kidney damage nephrotoxicant. Acute oral or parenteral exposure induces extensive kidney damage (Fowler and Woods, 1977; Goyer et al., 1975). Studies in vivo and in vitro have demonstrated that mercury induced lipid peroxidation, suggesting the involvement of oxidative stress in its cytotoxicity (Lund et al., 1991; Stacey and Kappus, 1982). Lund et al. (1991) reported that mercury enhances renal mitochondrial hydrogen peroxide formation in vivo and in vitro. However, cansative correlation between mercury induced lipid peroxidation and cellular toxicity remains controversial. Some authors reported that lipid peroxidation plays a critical role in cell injury induced by mercury (Lund et al., 1991) in renal cells, whereas other investigators showed that lipid peroxidation is not directly responsible for mercury induced cell injury in hepatocytes and renal cells (Paller, 1985; Strubell, 1996). It is important to develop an effective drug for mercury to prevent the mercury induced cellular damages.

Corresponding Author: Youcef Necib, Department of Biochemistry and Biological Cellular and Molecular,

Faculty of Sciences, Mentouri University, BP 25000 Constantine, Algeria 
Historically, plants have been used as folk medicine against various type of disease. Olive oil is an integral ingredient in the Mediterranean diet. There is growing evidence that it may have great health benefits including the reduction in coronary heart disease risk, the prevention of some cancers and the modification of immune and inflammatory responses (Visioli and Galli, 2002; Keys, 1995; Stark and Mader, 2002). Virgin olive oil appears to be a functional food with various components such as monounsaturated fatty acids that may have nutritional benefits. It is also a good source of phytochemicals, including polyphenolic compounds (Lavelli, 2002; Visioli and Galli, 1998). It is known that an increased consumption of Monounsaturated Fatty Acids (MUFA) instead of Polyunsaturated Fatty Acids (PUFA) reduces the risk of atherosclerosis because it decreases the circulating lipoprotein's sensitivity to peroxidation (Moreno and Mitjavilab, 2003).

Furthermore, the dietary MUFA healthy effects were attributed to decreased endothelial activation (Massaro and Caterina, 2002) and LDL susceptibility to oxidation (Bonanome et al., 1992). In recent years, scientists have focusedon the preventive effects of phenols against degenerative diseases mediated by the ROS. It has been reported that the phenolic compounds are able to interact with the biological systems and as bioactive molecules. They are particularly important inhibitors of lipid peroxidation (Salah et al., 1995) and are believed to be effective through their free radical scavenging and metal-chelating propertie (Kandaswami and Middleton, 1994; Rice-Evans et al., 1996). In experimental studies, olive oil phenolic compounds showed strong antioxidant properties against lipids, DNA and LDL oxidation (Covas et al., 2006). Hydroxytyrosol (2-(3,4 dihydroxyphenyl) Ethanol, DPE), one of the phenolic compounds present in extra virgin olive oil has been suggested to be a potent antioxidant, thus contributing to the beneficial properties of olive oil (Deiana et al., 1999). DPE administration has been shown to reduce the consequences of passive smoking-induced oxidative stress (Visioli et al., 2000), prevent LDL oxidation (Wiseman et al., 1996) and platelet aggregation and inhibit leukocyte 5lipoxygenases (De la Puerta et al., 1999). DPE has shown efficacy in preventing oxidative stress in the liver of rats intoxicated by cadmium (Casalino et al., 2002). In addition, when human hepatoma HepG2 cells were pretreated with DPE for 2 or $20 \mathrm{~h}$ prior to submission to tert-butylhydroperoxide-induced oxidative stress, cell toxicity was completely prevented, indicating that the antioxidant-treated cells were totally protected against the oxidative insult (Goya et al., 2007). However, the liver is not only the main target for phenolic antioxidants once absorbed from the gastrointestinal tract but is the major place for phenolic metabolism. Therefore, studies dealing with the effect of antioxidant dietary phenolics on the liver should be given priority. The literature data on olive oil polyphenols is mainly concerned with purified compounds, while the antioxidant properties of the total fraction of the lipophilic or hydrophilic components have been poorly investigated. Being a complex mixture of compounds, the study of the protective effect could be more representative than of a single component.

The purpose of this study was to evaluate the protective role of virgin olive oil on mercury chloride induced oxidative and renal stress in rats.

\section{MATERIALS AND METHODS}

The virgin olive oil used in this study originated from chetaibi (Algeria), it was extracted by a traditional method. All chemicals used in this study were purchased from sigma chemical company. Laboratory animals, Albino Wistar male rats, were brought from the Algiers Pasteur institute at the age of 8 weeks, with an average live weight of $200 \mathrm{~g}$. They were located in a room with an ambient temperature of $21 \pm 1^{\circ} \mathrm{C}$ and up to $12 \mathrm{~h}$ of light daily. The rats were divided into four experimental groups; each consists of eight rats. The first group was served as the control. The second group was given virgin olive oil at a dose of $2 \mathrm{~mL} \mathrm{~kg}^{-1}$ (Bouchefra and Idoui, 2012), body weight, while the third group $\left(\mathrm{HgCl}_{2}\right)$ was intraperitoneally given mercuric chloride at a dose of 0.5 $\mathrm{mg} \mathrm{kg}^{-1}$ body weight (Bensefa-colas et al., 2011). Finally, the fourth group was given combined treatment with virgin olive oil and mercuric chloride. The treatment of all groups was lasted for 2 consecutive weeks.

Twenty four hours after the last administration the blood was collected by retro- orbital sinus punction from each anesthetized rats. After centrifugation at $3000 \mathrm{rpm}$ for $10 \mathrm{~min}$, the serum was separated immediately and stored at $-20^{\circ} \mathrm{C}$ until determination of: IL1, IL6, TNF $\alpha$, urea, creatinine and uric acid. Subsequently, rats were decapitated and kidneys were removed.

\subsection{Tissue Preparation}

About $500 \mathrm{mg}$ of kidney was homogenized in $4 \mathrm{~mL}$ of buffer solution of phosphate buffered saline (w/v: $500 \mathrm{mg}$ tissue with $4 \mathrm{ml}$ PBS, PH 7.4) homogenates were centrifuged at $10.000 \mathrm{xg}$ for $15 \mathrm{~min}$ at $4^{\circ} \mathrm{C}$ and the resultant 
supernatant was used for determination of: Reduced Glutathione (GSH), Thiobarbituric Acid-Reactive Substance (TBARS) level and Glutathione Peroxidase (GSH-PX) and Glutathione-S-Transferase (GST) activities.

\subsection{Determination of Biochemical Parameters}

Serum urea, creatinine and uric acid were determined using commercial kits (Spinreact) and serum IL1, IL6, TNF $\alpha$ levels were assayed using specific Elisa kits for each cytokine (Boster, immunoleader).

\subsection{Determination of Lipid Peroxidation (LPO)}

Lipid peroxidation level in the liver was measured by the method of Buege and Aust (1984). About $125 \mu \mathrm{L}$ of supernatant were homogenized by sonication with $50 \mu \mathrm{L}$ of PBS, $125 \mu \mathrm{L}$ of $20 \%$ TCA + BHT 1\% (TCA-BHT) in order to precipitate proteins and centrifuged (1000 xg, 10 min, $4^{\circ} \mathrm{C}$ ), afterwards, $200 \mu \mathrm{L}$ of supernatant were mixed with $40 \mu \mathrm{L}$ of $\mathrm{HCl}(0,6 \mathrm{M})$ and $160 \mu \mathrm{L}$ of TBA dissolved in tris $(120 \mathrm{mM})$ and then the mixture was heated at $80^{\circ} \mathrm{C}$ for $10 \mathrm{~min}$, the absorbance of the resultant supernatant was obtained at $530 \mathrm{~nm}$. The amount of TBARS was calculated using a molar extinction coeffient of $1.56 \times 10^{5} \mathrm{M} / \mathrm{Cm}$.

\subsection{Determination of Reduced Glutathione (GSH)}

GSH content in liver was measured spectrophotometrically by using Ellman's reagent (DTNB) as a colouring reagent, following the method described by Weckbercker and Cory (1988).

\subsection{Determination of Glutathione-S- Transferase (GST) (EC2.5.1.18)}

The cytosolic glutathione-S-transferase activity was determined spectrophotometrically at $37^{\circ} \mathrm{C}$ by method of Habig and Jakoby (1974). The reaction mixture (1 mL) contained $0.334 \mathrm{~mL}$ of $100 \mathrm{mM}$ phosphate buffer $(\mathrm{PH}$ 6.5), $0.033 \mathrm{~mL}$ of $30 \mathrm{mM} \mathrm{CDNB}$ and $0.33 \mathrm{~mL}$ of reduced Glutathione. After pre-incubating the reaction mixture for $2 \mathrm{~min}$ the reaction was started by adding $0.01 \mathrm{~mL}$ of diluted cytosol and the absorbance was followed for $3 \mathrm{~min}$ at $340 \mathrm{~nm}$. The specific activity of GST is expressed as $\mu$ mole of GSH-CDNB conjugate formed $/ \mathrm{min} / \mathrm{mg}$ protein using extinction coefficient of $9.6 \mathrm{Mm}^{-1} \mathrm{~cm}^{-1}$

\subsection{Determination of GSH-Px (E.C.1.11.1.9)}

Glutathione peroxidase (EC 1.11.1.9) activity was modified from the method of Flohe and Gunzler (1984). for the enzyme reaction , $0.2 \mathrm{~mL}$ of the supernatant was placed into a tube and mixed with $0.4 \mathrm{~mL} \mathrm{GSH}$ (reduced glutathione, sigma product, analytical grade) and the mixture was put into an ice bath for $30 \mathrm{~min}$. then the mixture was centrifuged for $10 \mathrm{~min}$ at $3000 \mathrm{rpm}, 0.48 \mathrm{ml}$ of the supernatant was placed into a cuvette and $2.2 \mathrm{~mL}$ of $0.32 \mathrm{M} \mathrm{Na}_{2} \mathrm{HPO}_{4}$ and $0.32 \mathrm{~mL}$ of $1 \mathrm{~m} \mathrm{moL} / 1$ 5,5'dithio-bis(2-nitrobenzoic acid) (DTNB, sigma) were added for color development. The absorbance at wavelength $412 \mathrm{~nm}$ was measured with a UV spectrophotometer after $5 \mathrm{~min}$. The enzyme activity was calculated as a decrease in GSH within the reaction time as compared to that in the non-enzyme reaction.

\subsection{Protein Quantification}

Protein was measured by the method of Bradford (1976) using bovine serum albumin as the standard.

\subsection{Statistical Analysis}

The data were subjected to student $t$ test for comparison between groups. The values are expressed as mean \pm SEM. Significance level was set at $p<0.05$, $\mathrm{p}<0.01, \mathrm{p}<0.001$.

\section{RESULTS}

\subsection{Effects of Treatments on Body, Absolute and Relative Kidney Weights}

Table 1 shows the effect of mercuric chloride, virgin olive oil and combined treatment with virgin olive oil and mercuric chloride. The marked decreased in rats body weight was observed in mercuric chloride treated rats and virgin olive oil + mercuric chloride group, but the result was not significant as compared to control. Along virgin olive oil showed increased body weight but result was not significant. The kidneys of rats treated with mercuric chloride were enlarged. Mercuric chloride treated rats showed increase in kidney weight and relative kidney weight as compared to control. Combined treatment with virgin olive oil showed significant increased relative kidney weight, while alone virgin olive oil treatment had showed no significant effect.

\subsection{Effects of Treatment on Serum Biochemical Parameters}

A significant elevation in serum IL1, IL6, TNF $\alpha$, urea, creatinine and uric acid levels was observed in mercuric chloride intoxicated rats. Only virgin olive oil treatment did not show any significant alteration. However, the combined treatment of virgin olive oil with mercuric chloride show a significant decline in serum IL1, IL6, TNF $\alpha$, urea, creatinine and uric acid levels was noticed respect to controls (Table 2). 
Table 1. Changes in body and absolute and relative kidney weights of control and rats treated with olive oil, mercuric chloride and combined treatment of mercuric chloride with olive oil after 2 weeks of treatment

\begin{tabular}{llccc}
\hline & Treatment groups & & & \\
& & & \\
Parameters & Control & olive oil & $\mathrm{HgCl}_{2}$ olive & oil $\mathrm{HgCl}_{2}$ \\
\hline Initial body weight $(\mathrm{g})$ & $172 \pm 46.3$ & $176.6 \pm 45.4$ & $171.3 \pm 52.6$ & $177.4 \pm 50.3$ \\
Final body weight $(\mathrm{g})$ & $175.4 \pm 75.9$ & $179.1 \pm 32.3$ & $176.1 \pm 42.2$ & $173.6 \pm 41.1$ \\
Absolute kidney weight (g) & $0.78 \pm 0.09$ & $1.02 \pm 0.12$ & $0.86 \pm 0.14$ & $0.88 \pm 0.20$ \\
Relative kidney weight (g/100g b.w) & $0.45 \pm 0.01$ & $0.57 \pm 0.03$ & $0.5 \pm 0.06$ & $0.49 \pm 0.04$ \\
\hline
\end{tabular}

Table 2. Changes in biochemical parameters of control and rats treated with olive oil, mercuric chloride and combined treatment of mercuric chloride with olive oil after 2 weeks of treatment.

\begin{tabular}{|c|c|c|c|c|}
\hline \multirow[b]{2}{*}{ Parameters } & \multicolumn{4}{|c|}{ Treatment groups } \\
\hline & Control & olive oil & $\mathrm{HgCl}_{2}$ 0live & $\mathrm{oil}+\mathrm{HgCl}_{2}$ \\
\hline Urea $(\mathrm{g} / \mathrm{l})$ & $0.38 \pm 0.04$ & $0.37 \pm 0.02$ & $0.46 \pm 0.04 * *$ & $0.45 \pm 0.03^{*}$ \\
\hline Creatinine (mg/l) & $2.17 \pm 0.69$ & $2.8 \pm 0.61$ & $3.10 \pm 0.72 *$ & $2.91 \pm 0.60$ \\
\hline Uric acid (mg/l) & $25.92 \pm 10.2$ & $22.26 \pm 2.8$ & $27.97 \pm 3.96$ & $26.6 \pm 6.93$ \\
\hline $\operatorname{IL} 1(\mathrm{pg} / \mathrm{ml})$ & $0.087 \pm 0.01$ & $0.085 \pm 0.01$ & $0.108 \pm 0.03$ & $0.103 \pm 0.03$ \\
\hline IL6(pg/ml) & $0.152 \pm 0.09$ & $0.162 \pm 0.06$ & $0.217 \pm 0.18$ & $0.174 \pm 0.09$ \\
\hline $\mathrm{TNF} \alpha(\mathrm{pg} / \mathrm{ml})$ & $0.078 \pm 0.01$ & $0.084 \pm 0.01$ & $0.293 \pm 0.26$ & $0.091 \pm 0.08$ \\
\hline
\end{tabular}

Values are given as mean \pm SEM for group of 6 animals each. ${ }^{*} \mathrm{P} \leq 0.05$, compared to controls. ${ }^{*} \mathrm{P} \leq 0.01$, compared to controls.

$* * * \mathrm{P} \leq 0.001$, compared to controls
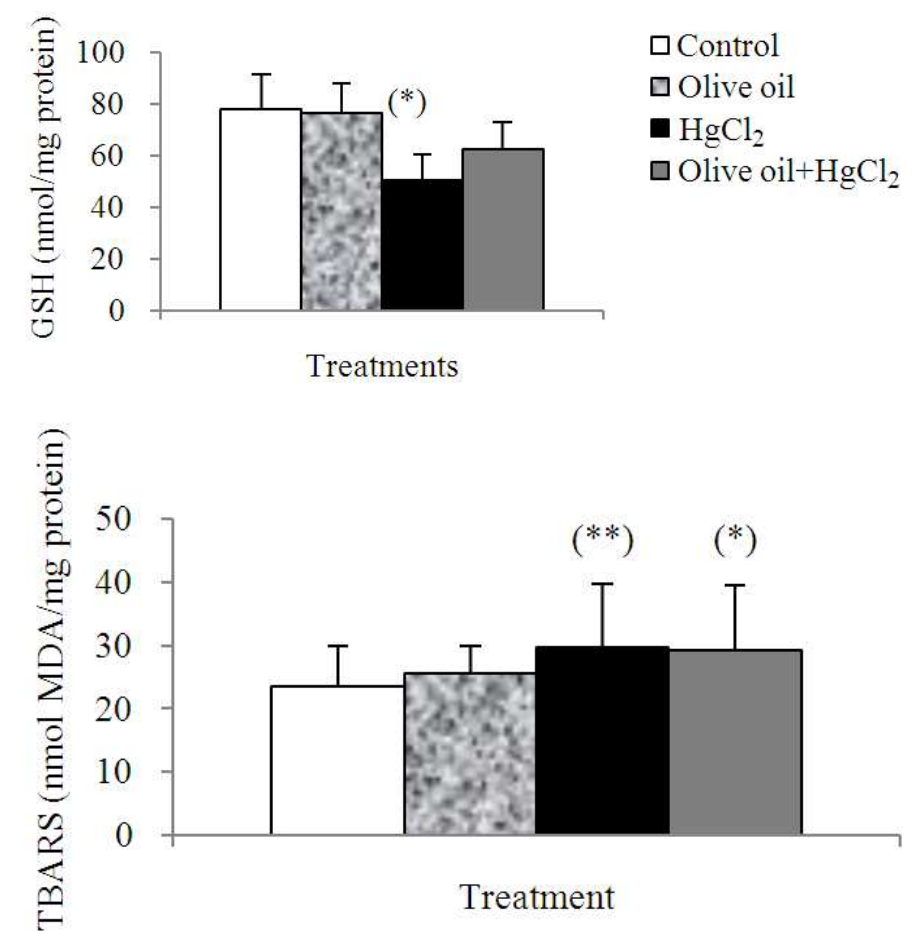

Fig. 1. Reduced glutathione (nmol/mg protein) and TBARS (nmol MDA/mg protein) levels in kidney of control and rats treated with olive oil, mercuric chloride and combined treatment of mercuric chloride with olive oil after 2 weeks of treatment. Values are given as mean \pm SEM for group of 6 animals each significant difference: * compared to controls $\left({ }^{*} \mathrm{p} \leq 0.05\right.$; $* * \mathrm{p} \leq 0.01 ; * * * \mathrm{p} \leq 0.001)$ 

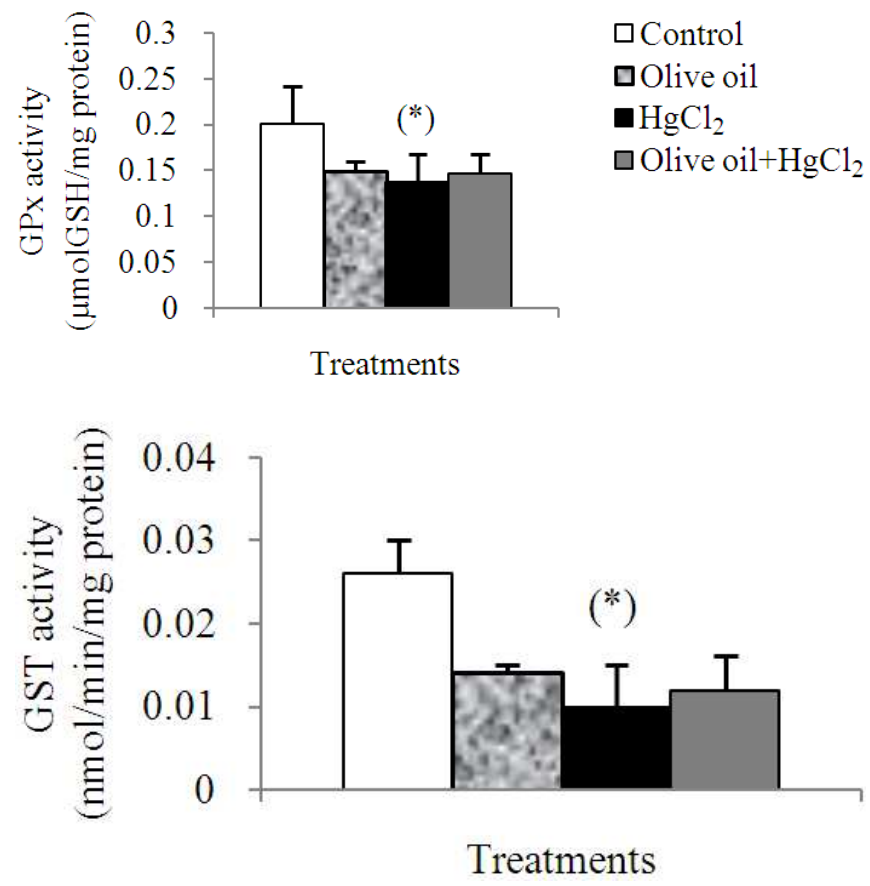

Fig. 2. Enzyme activities of GPx ( $\mu \mathrm{mol} \mathrm{GSH} / \mathrm{mg}$ protein) and GST (nmol/min/mg protein) in kidney of control and rats treated with olive oil, mercuric chloride and combined treatment of mercuric chloride with olive oil after 2 weeks of treatment. Values are given as mean \pm SEM for group of 6 animals each significant difference: ${ }^{*}$ compared to controls $\left({ }^{*} \mathrm{p} \leq 0.05 ;{ }^{*} \mathrm{p} \leq 0.01\right.$; $* * * \mathrm{p} \leq 0.001)$

\subsection{Effects of Treatments on Renal Oxidative Stress Parameters}

Mercuric chloride exposure a significant depleted in reduced glutathione level, GSH-Px and GST activities and a highly significant increase in kidney lipid peroxidation level in mercury intoxicated rats was noticed. Virgin olive oil alone treatment did not show any significant decline. Combined treatment of mercuric chloride with virgin olive oil, increase reduced glutathione level, GSH-Px and GST activities and a significant depletion in lipid peroxidation level was recorded with respect to the control (Fig. 1 and 2).

\section{DISCUSSION}

In the present study, oxidative stress induced by $\mathrm{HgCl}_{2}$ was evidenced in kidney of rats by increase in lipid peroxidation level and the stimulation of GSH-Px, GST and catalase activities. Accordingly, oxidative stress induced by $\mathrm{HgCl}_{2}$ has been previously reported (Lund et al., 1991; Sener et al., 2007). As a consequence of lipid peroxidation biological memranes are affected causing cellular damage. In the present study, serum urea, creatinine, uric acid levels were significantly increased after 2 weeks mercuric chloride $\left(0.5 \mathrm{mg} \mathrm{kg}^{-1}\right)$, showing insufficiency of renal function. Studies in animals have established that tubular injury plays a central role in the reduction of glomerular filtration rate in acute tubular necrosis. Two major tubular abnormalities could be involved in the decrease in glomerular function in mercuric chloride treated rats: Obstruction and backleak of glomerular Filtrate (Girardi and Elias, 1995). The alterations in glomerular function in mercuric chloride treated rats may also be secondary to ROS(reactive oxygen species), which induce mesangial cells contraction, altering the filtration surface area and modifying the ultrafiltration coefficient factors that decrease the glomerular filtration rat (Stohs and Bagchi, 1995; Zalups, 2000). Elevated serum level of the cytokine IL1, IL6 and TNF $\alpha$ demonstrated the severity of $\mathrm{Hg}$ induced system inflammatory response. Virgin olive oil as an antioxidant agent, ameliorated oxidative injury in the tissues and functional deteriorated. Both clical event is perceived by tissue macrophages and monocytes, which in turn secrete cytokines such as 
interleukine1, interleukine 6 and TNF $\alpha$ (Ziembia et al., 2005), indicating the role of this cytokine in this toxicity, while virgin olive oil depressed the IL1, IL6 and TNF $\alpha$ levels response. Thus, it seens likely that the alleviation of $\mathrm{Hg}$ induced oxidative tissue damage by virgin olive oil involves the suppression of a variety of proinflammatory mediators produced by leukocytes and macrophages. The activity of GSH-Px and GST that can clear to protect the cells from being injured represents the competence of clearing free radicals from the organism. MDA content manifests the level of lipid peroxidation and then indirectly represents the level of damage of the cell of renal mitochondria. Evaluating from GSH, MDA levels and GSH-Px, GST activities in kidney of rats. $\mathrm{Hg}$ alone significantly decreased GSH level, GSH-Px and GST activities and increased MDA content along with histological damage in kidney.

Co-administration of virgin olive oil and $\mathrm{Hg}$ significantly increased GSH level and activities of GSHPx and GST and decreased MDA content.

Several studies have demonstrated the ability of olive oil to inhibit oxidative stress in the liver through various mechanisms (Kyle et al., 1987).

Moreover, we have shown that the oral supplementation of olive oil to rats administered ethanol chronically restored damage caused to the liver by inhibiting lipid peroxidation and improving enzymatic activities (Thabrew et al., 1987). The mechanism proposed to explain the positive effects of olive oil may be attributed to its richness in MUFA, mainly oleic acid which has different effects on lipid profiles and peroxidation in rabbit hepatic mitochondria (Kasdallah-Grissa et al., 2008). Indeed, EVOO contains a considerable amount of oleuropein, hydroxytyrosol, tyrosol and caffeic acid which all have potent inhibition effects against ROS (OchoaHerrera et al., 2001; Owen et al., 2000). Hydroxytyrosol is highly effective against DNA damage by peroxynitrite in vitro (Deiana et al., 1999). Caffeic acid phenethyl ester and its related compounds limit the functional alterations of the isolated mouse brain and liver mitochondria submitted to in vitro anoxiareoxygenation (Feng et al., 2008). Lipid peroxidation is the process of oxidative degradation of PUFA and its incidence in biological membranes resulting in impaired membrane function, structural integrity, decreased membrane fluidity and the inactivation of several membrane-bound enzymes (Gutteridge and Halliwell, 2000). Therefore, some particular attention was given to the liver's fatty acid composition in rats used in the current experiment. In healthy humans, the short-term consumption of olive oil decreased serum oxidative stress (Weinbrenner et al., 2004) and their isolated lipoprotein fractions; LDL and HDL were shown to be enriched with oleic acid and resistant to oxidation (Aviram et al., 1993; Sola et al., 1997). Moreover, PUFAs are more susceptible to peroxidation resulting in MDA formation in mammalian tissues. In fact, because of their peculiar structure -that is the presence of one or more double bonds-UFA are more susceptible to free radical damage and thus could increase the susceptibility of LDL particles to oxidation. Most of the studies comparing the effects of a MUFA-rich diet with PUFArich diet on LDL oxidation parameters have found a higher resistance of LDL particles to oxidation after the consumption of MUFA-rich diet (Esterbauer et al., 1991; Aguilera et al., 2004). Finally, the health effects of dietary MUFA, including lower endothelial activation (Massaro and Caterina, 2002) and susceptibility of LDL to oxidation (Esterbauer et al., 1991; Aguilera et al., 2004) are indeed to be considered. Nevertheless, it is also remarkable to establish the amount and quality of phenolic compounds in virgin olive oil.

\section{CONCLUSION}

It may be concluded that combined treatment of virgin olive oil has a preventive and protective effect on mercuric chloride induced oxidative stress. More-over, it protects from $\mathrm{HgCl}_{2}$ induced renal dysfunction and executes its modulatory role in mercury induced free radical production.

\section{REFERENCES}

Aguilera, C.M., M.D. Mesa, M.C. Ramirez-Tortosa, M.T. Nestares and E. Ros et al., 2004. Sunflower oil does not protect against LDL oxidation as virgin olive oil does in patients with peripheral vascular disease. Clin. Nutr., 23: 673-681. DOI: 10.1016/j.clnu.2003.11.005

Aviram, M. and K. Eias, 1993. Dietary olive oil reduces low-density lipoprotein uptake by macrophages and decreases the susceptibility of the lipoprotein to undergo lipid peroxidation. Annals Nutr. Metab., 37: 75-84. DOI:10.1159/000177753

Bensefa-colas, L., P. andujar and A. Descatha, 2011. Mercury poisoning. Revue Med. Interne, 32: 416424. DOI: 10.1016/j.revmed.2009.08.024 
Bonanome, A., A. Pagnan, S. Biffanti, A. Opportuno and F. Sorgato et al., 1992. Effect of dietary monounsaturated and polyunsaturated fatty acids on the susceptibility of plasma low density lipoproteins to oxidative modification. Arteriosclerosis Thrombosis, 12: 529533. DOI: 10.1161/01.ATV.12.4.529

Bouchefra, A. and T. Idoui, 2012. Nutritional effect of virgin olive oil on growth performance, plasma lipids and endogenous microflora of wistar rats. Techniol. Laboratoire, 7: 1-7.

Bradford, M.A., 1976. A rapid and sensitive method for the quantitation of microgram quantities of protein utilizing the principle of protein-dye binding. Anal. Biochem., 72: 248-254. DOI: 10.1016/00032697(76)90527-3

Buege, J.A. and S.D. Aust, 1984. Microsomal lipid peroxidation. Methods Enzymol., 105: 302-310.

Casalino, E., G. Calzaretti, C. Sblano and C. Landriscina, 2002. Molecular inhibitory mechanism antioxidant enzymes in rat liver and kidney by cadmium. Toxicology, 179: 37-50.

Covas, M.I., V. Ruiz-Gutiérrez, R.DL. Torre, A. Kafatos and R.M. Lamuela-Raventos et al., 2006. Minor components of olive Oil: Evidence to date of health benefits in humans. Nutr. Rev., 64: 20-30. DOI: 10.1301/nr.2006.oct.S20-S30

De la Puerta, R., V. Ruiz Gutierrez and J.R.S. Hoult, 1999. Inhibition of leukocyte 5-lipoxygenase by phenolics from virgin olive oil. Biochemical Pharmacol., 57: 445-449. DOI: 10.1016/S0006-2952(98)00320-7

Deiana, M., O.I. Aruoma, M.D.L.P. Bianchi, J.P. Spencer and H. Kaur et al., 1999. Inhibition of peroxynitrite dependent DNA base modification and tyrosine nitration by the extra virgin olive oil-derived antioxidant hydroxytyrosol. Free Radical Biol. Med., 26: 762-769. DOI: 10.1016/S0891-5849(98)00231-7

Esterbauer, H., R.J. Schaur and H. Zollner, 1991. Chemistry and biochemistry of 4-hydroxynonenal, malonaldehyde and related aldehydes. Free Radical Biol. Med., 11: 8188. DOI: 10.1016/0891-5849(91)90192-6

Feng, Y., Y.W. Lu, P.H. Xu, Y. Long and W.M. Wu et al., 2008. Caffeic acid phenethyl ester and its related compounds limit the functional alterations of the isolated mouse brain and liver mitochondria submitted to in vitro anoxia-reoxygenation: Relationship to their antioxidant activities. Biochimical Biophys. Acta, 1780: 659-672. DOI: 10.1016/j.bbagen.2008.01.002

Flohe, L. and W.A. Gunzler, 1984. Assays of glutathione peroxidase. Methods Enzymol., 105: 114-121. DOI: 10.1016/S0076-6879(84)05015-1
Fowler, B.A. and J.S. Woods, 1977. Ultrastructural and biochemical changes in renal mitochondria during chronic oral methyl mercury exposure: The relationship to renal function. Exp. Mol. Pathol., 27: 403-412. DOI: 10.1016/0014-4800(77)90010-7

Girardi, G. and M.M. Elias, 1995. Mercuric chloride effects on rat renal redox enzymes activities: SOD protection. Free Radical Biol. Med., 18: 61-66. DOI: 10.1016/0891-5849(94)00097-4

Goya, L., R. Mateos and L. Bravo, 2007. Effect of the olive oil phenol hydroxytyrosol on human hepatoma $\mathrm{HepG}_{2}$ cells. Eur. J. Nutr., 46: 70-78. DOI: 10.1007/s00394-006-0633-8

Goyer, R.A. and B.C. Rhune, 1975. Toxic Changes in Mitochondrial Membranes and Mitochondrial Function. In: Pathobiology of Cell Membranes, Trump, B.F. and A.U. Arstilla (Eds.), Academic Press, New York, ISBN-10: 0127015019.

Gutteridge, J.M.C. and B. Halliwell, 2000. Free radicals and antioxidants in the year 2000: A historical look to the future. Annals NY Acad. Sci., 899: 136-147. DOI: $10.1111 /$ j.1749-6632.2000.tb06182.x

Habig, W.H. and W.B.P. Jakoby, 1974. Glutathione-Stransferase the first step in mercapturic acid formation. J. Biol. Chem., 249: 7130-7139. PMID: 4436300

Kandaswami, C. and E.J.R. Middleton, 1994. Free radical scavenging and antioxidant activity of plant flavonoids. Adv. Exp. Med. Biol., 366: 351-376. DOI: 10.1007/978-1-4615-1833-4_25

Kasdallah-Grissa, A., A. Nakbi, N. Koubâa, S. El-Fazaâ and N. Gharbi et al., 2008. Dietary virgin olive oil protects against lipid peroxidation and improves antioxidant status in the liver of rats chronically exposed to ethanol. Nutr. Res., 28: 472-479. DOI: 10.1016/j.nutres.2008.03.014

Keys, A., 1995. Mediterranean diet and public health: Personal reflections. Am. J. Clin. Nutr., 61: 1321S1323S. PMID: 7754982

Kyle, M.E., S. Miccadei, D. Nakae and J.L. Farber, 1987. Superoxide dismutase and catalase protect cultured hepatocytes from the cytotoxicity of acetaminophen. Biochemical Biophys. Commun., 149: 889-896. DOI: 10.1016/0006-291X(87)904918

Lavelli, V., 2002. Comparison of the antioxidant activities of extra virgin olive oils. J. Agric. Food Chem., 50: 7704-7708. DOI: 10.1021/jf020749o

Lund, B.O., D.M. Miller and J.S. Woods, 1991. Mercury-induced $\mathrm{H}_{2} \mathrm{O}_{2}$ production and lipid peroxidation in vitro in rat kidney mitochondria. Biochemical Pharmacol., 42: S181-S187. DOI: 10.1016/0006-2952(91)90408-W 
Massaro, M. and R.D. Caterina, 2002. Vasculoprotective effects of oleic acid: Epidemiological background and direct vascular antiatherogenic properties. Nutr. Metab. Cardiovascular Dis., 12: 42-51. PMID: 12125230

Moreno, J.J. and M.T. Mitjavilab, 2003. The degree of unsaturation of dietary fatty acids and the development of atherosclerosis. J. Nutr. Biochemical, 14: 182-195. DOI: 10.1016/S0955-2863(02)00294-2

Ochoa-Herrera, J.J., J.R. Huertas, J.L. Quiles and J. Mataix, 2001. Dietary oils high in oleic acid, but with different non-glyceride contents, have different effects on lipid profiles and peroxidation in rabbit hepatic mitochondria. J. Nutr. Biochemical, 12: 357364. DOI: 10.1016/S0955-2863(01)00150-4

Owen, R.W., A. Giacosa, W.E. Hull, R. Haubner and G. Wurtele et al., 2000. Olive-oil consumption and health: The possible role of antioxidant. Lancet Oncol., 1: 107112. DOI: $10.1016 / \mathrm{S} 1470-2045(00) 00015-2$

Paller, M.S., 1985. Free radical scavengers in mercuric chloride-induced acute renal failure in the rat. J. Laboratory Clin. Med., 105: 459-463. PMID: 3920337

Rice-Evans, C.A., N.J. Miller and G. Paganga, 1996. Structure-antioxidant activity relationships of flavonoids and phenolic acids. Free Radical Biol. Med., 20: 933-956. DOI: 10.1016/08915849(95)02227-9

Salah, N., N.J. Miller, G. Paganga, L. Tijburg and G.P. Bolwell et al., 1995. Polyphenolic flavanols as scavengers of aqueous phase radicals and as chainbreaking antioxidants. Arch. Biochem. Biophys., 322: 339-346. DOI: 10.1006/abbi.1995.1473

Sener, G., O. Sehirli, A. Tozan, A. Velioglu-ovuç and N. Gedik et al., 2007. Ginkgo biloba extract protects against mercury(II)-induced oxidative tissue damage in rats. Food Chemical Toxicol., 45: 543-550. DOI: 10.1016/j.fct.2006.07.024

Sola, R., A.E. LaVille, J.L. Richard, C. Motta and M.T. Bargallo et al., 1997. Oleic acid rich diet protects against the oxidative modification of high density lipoprotein. Free Radical Biol. Med., 22: 1037-1045. DOI: 10.1016/S0891-5849(96)00490-X

Stacey, N.H. and H. Kappus, 1982. Cellular toxicity and lipid peroxidation in response to mercury. Toxicol. Applied Pharmacol., 63: 29-35. DOI: 10.1016/0041008X(82)90023-0

Stark, A.H. and Z. Mader, 2002. Olive oil as a functional food: Epidemiology and nutritional approaches. Nutr. Rev., 60: 170-176. DOI: $10.1301 / 002966402320243250$
Stohs, S.J. and D. Bagchi, 1995. Oxidative mechanisms in the toxicity of metal ions. Free Radical Biol. Med., 18: 321-336. DOI: 10.1016/08915849(94)00159-H

Strubell, O., 1996. Comparative studies on the toxicity of mercury, cadmium and copper toward the isolated perfused rat liver. J. Toxicol. Environ. Health, 47: 267-283. DOI: 10.1080/009841096161780

Thabrew, M.I., P.D. Joice and W.A. Rajatissa, 1987. A comparative study of the efficacy of Pavetta indica and Osbeckia octandra in the treatment of liver dysfunction. Planta Med., 53: 239-241. DOI: 10.1055/s-2006-962691

Visioli, F. and C. Galli, 1998. The effect of minor constituents of olive oil on cardiovascular disease: New findings. Nutr. Rev., 56: 142-147. DOI: 10.1111/j.1753-4887.1998.tb01739.x

Visioli, F. and C. Galli, 2002. Biological properties of olive oil phytochemicals. Critical Rev. Food Sci. Nutr., 42: 209-221. DOI: 10.1080/10408690290825529

Visioli, F., C. Galli, E. Plasmati, S. Viappiani and A. Hernandez et al., 2000. Olive phenol hydroxytyrosol prevents passive smoking-induced oxidative stress. Circulation, 102: 2169-2171. DOI: 10.1161/01.CIR.102.18.2169

Weckbercker, G. and J.G. Cory, 1988. ribonucleotidereductase activity and growth of glutathione-depended mouse leukaemia L 1210 cells in vitro. Cancer Lett., 40: 257-264.

Weinbrenner, T., M. Fito, R. De La Torre, G.T. Saez and P. Rijken et al., 2004. Olive oils high in phenolic compounds modulate oxidative/antioxidative status in men. J. Nutr., 134: 2314-2321. PMID: 15333722

Wiseman, S.A., J.N. Mathot, N.J. De Fouw and L.B. Tijburg, 1996. Dietary non-tocopherol antioxidants present in extra virgin olive oil increase the resistance of low density lipoproteins to oxidation in rabbits. Atherosclerosis, 120: 15-23. DOI: 10.1016/0021-9150(95)05656-4

Zalups, P.K., 2000. Molecular interactions with mercury in the kidney. Pharmacol. Rev., 52: 113-143. PMID: 10699157

Ziembia, S.E., J.R. McCabe and A.J. Rosenspire, 2005. Inorganic mercury dissociates preassembled Fas/CD95 receptor oligomers in $\mathrm{T}$ lymphocytes. Toxicol. Applied Pharmacol., 206: 334-342. DOI: 10.1016/j.taap.2004.11.014 